\title{
The potential influence of understory management patterns on soil nutrients and C:N:P stoichiometry in an urban forest
}

\author{
Tingting Tao ${ }^{1}$, Ze Wang ${ }^{1}$, Yizhu Wang ${ }^{1}$, Gaston E. Small ${ }^{2}$, Jihui Chen ${ }^{3}$, and Xiao Sun ${ }^{1}$ \\ ${ }^{1}$ Nanjing Agricultural University \\ ${ }^{2}$ University of St Thomas \\ ${ }^{3}$ Guizhou University
}

February 18, 2022

\begin{abstract}
Forest vegetation management plays an important role in maintaining soil health and function. In highly-managed urban forests, the clearing of understory vegetation has potential to cause loss of soil nutrients, resulting in stoichiometric imbalances and a decrease in soil function. Therefore, studying how to effectively manage understory to improve soil quality is critical for stability and function of urban forest. Here, we collected soil samples from a plantation forest in Zijin Shan National Forest Park in two stands, each with three adjacent plots with different understory management practices: one with high diversity natural understory vegetation, another with low diversity managed understories of ornamental groundcover (Reineckia carnea (Andr.) Kunth or Ophiopogon bodinieri Levl.), and a third with cleared understory. Compared to plots with natural understories, we found lower levels of soil total carbon $(\mathrm{C})$, total nitrogen $(\mathrm{N})$, and some their fractions especially microbial $\mathrm{C}$ and $\mathrm{N}$, in plots with no understories. Correspondingly, ratios of soil C: phosphorus $(\mathrm{P})$ and $\mathrm{N}: \mathrm{P}$, and microbial C:N, were lower in the absence of understories in one of the two stands. These influences were smaller with ground-cover plants in both stands, particularly O. bodinieri. The magnitude of these effects differed between the two stands, with greater effects observed in the stand with higher soil C. While we cannot rule out the effects of other influences on soil properties, these results offer support for the hypothesis that human management practices affect urban forest soil properties and microorganisms, and that appropriate understory managements can alleviate these adverse influences.
\end{abstract}

\section{Hosted file}

MS-2021.10.18.docx available at https://authorea.com/users/461203/articles/556957-thepotential-influence-of-understory-management-patterns-on-soil-nutrients-and-c-n-pstoichiometry-in-an-urban-forest 

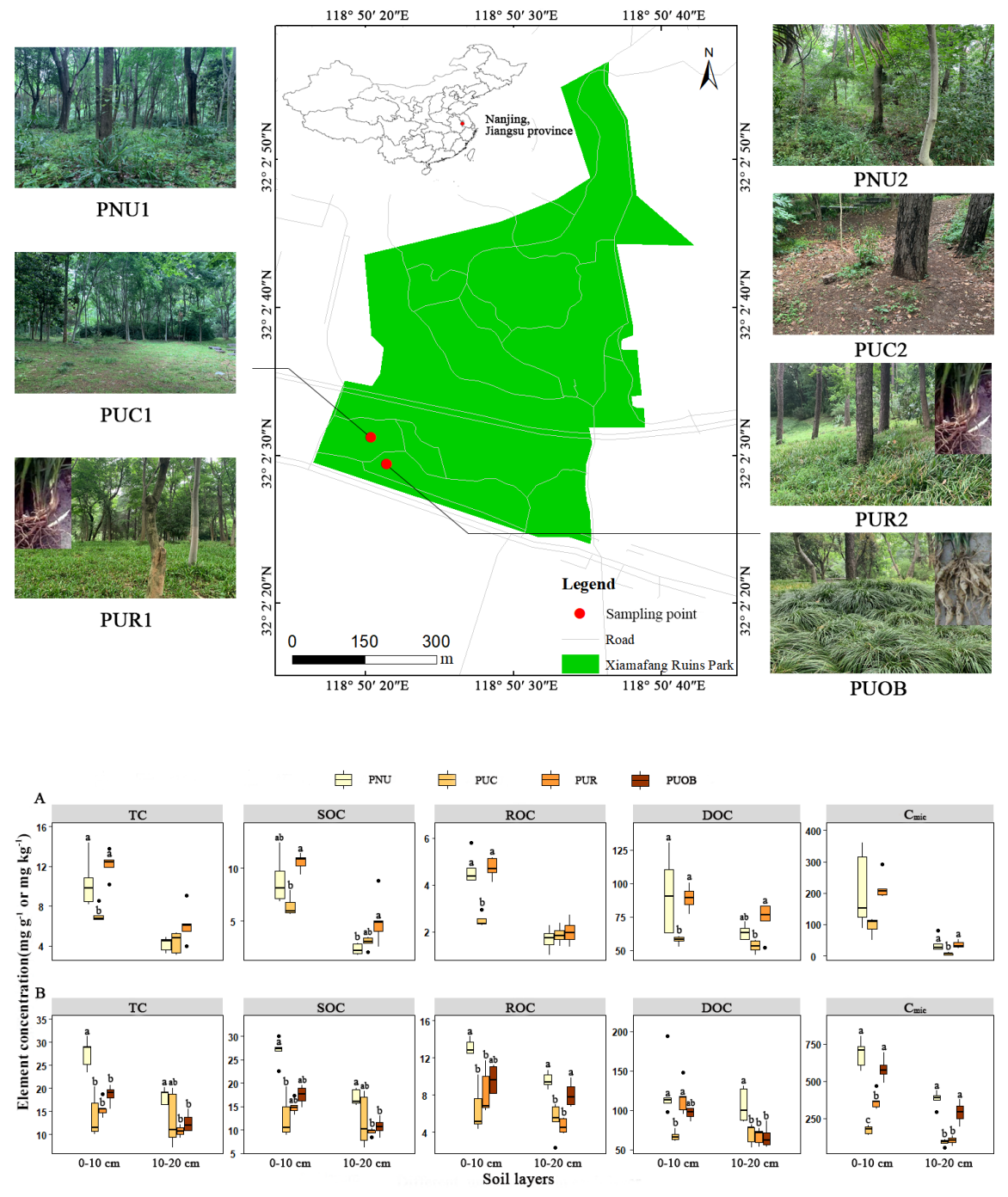


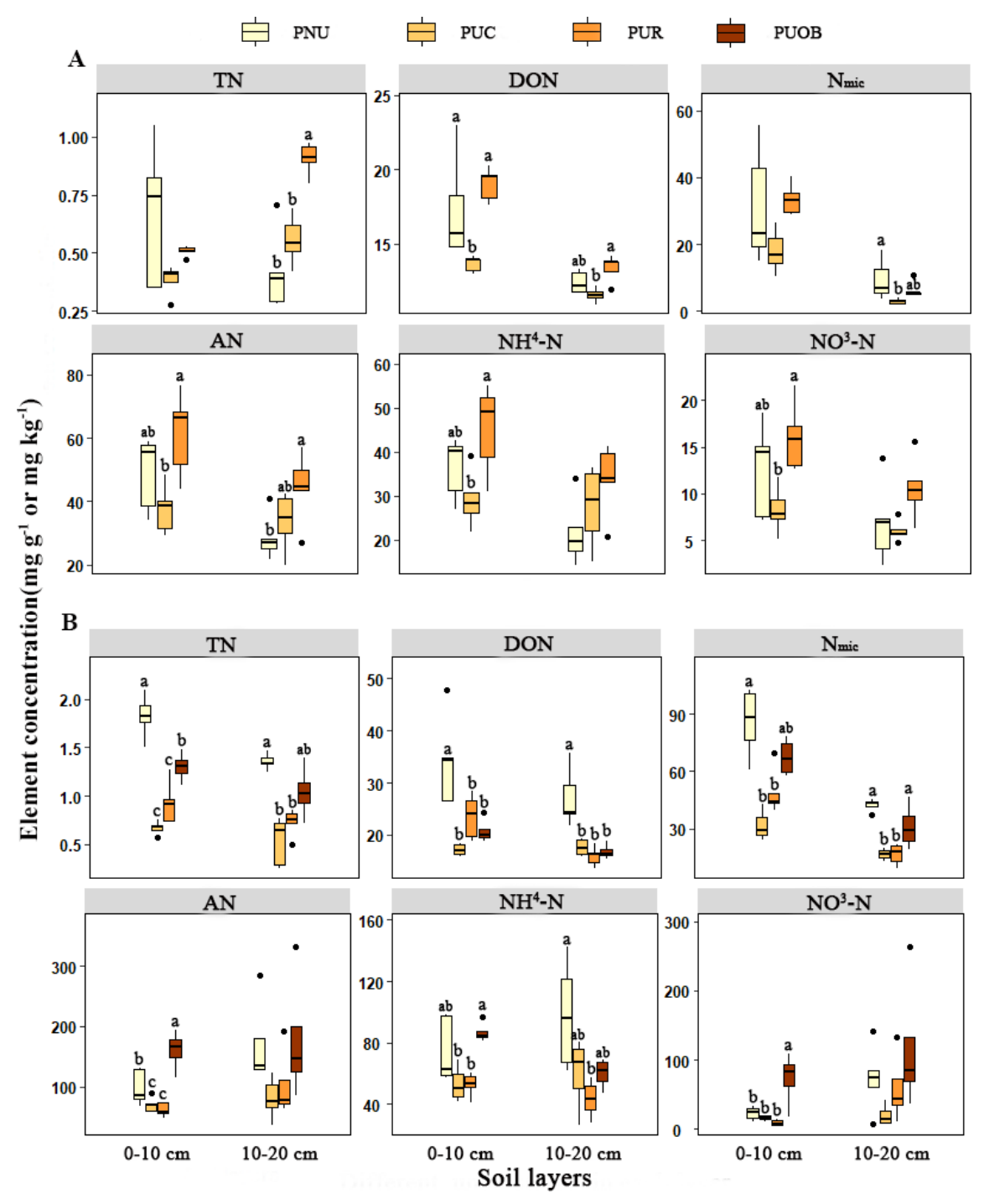



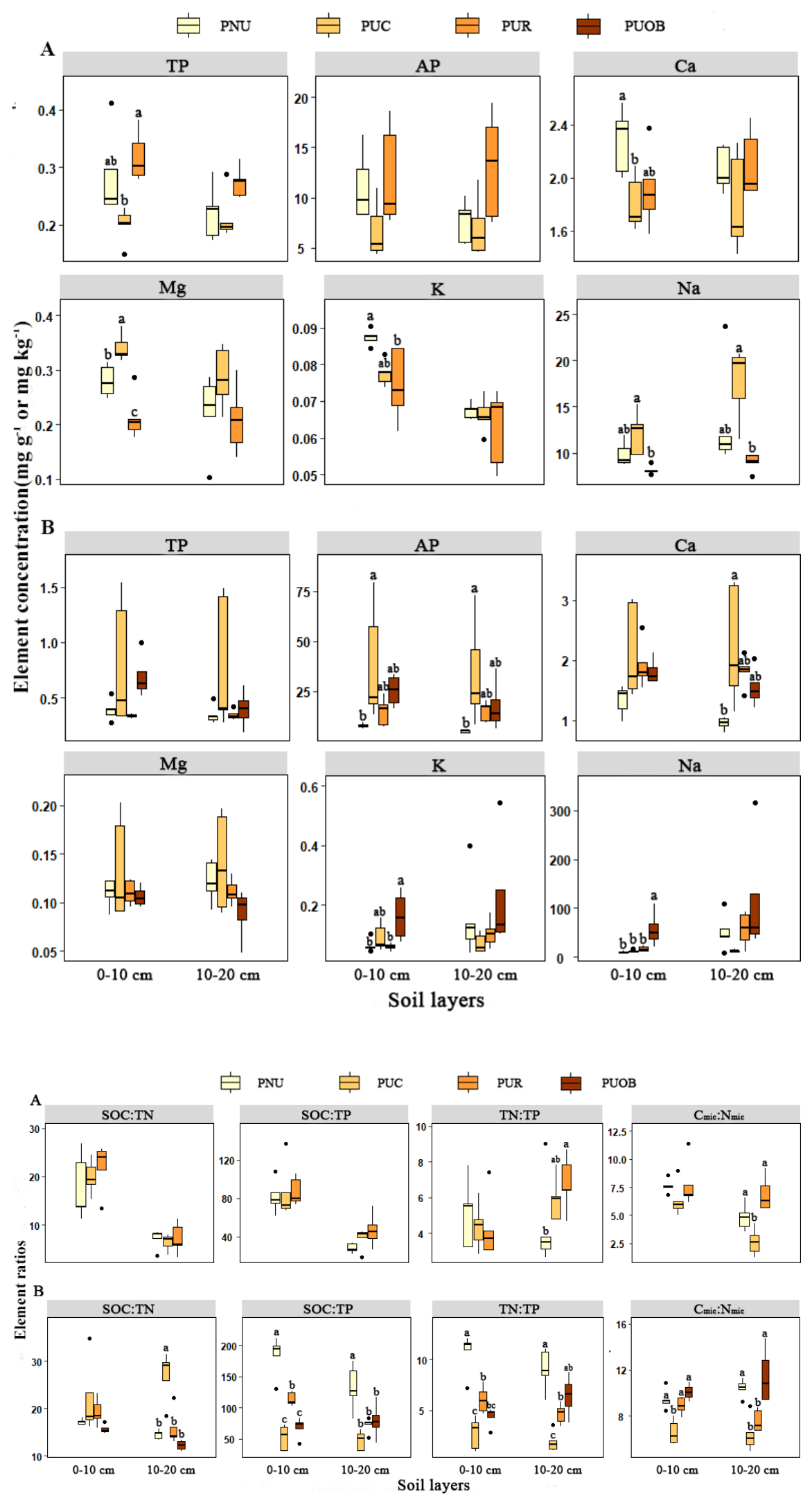

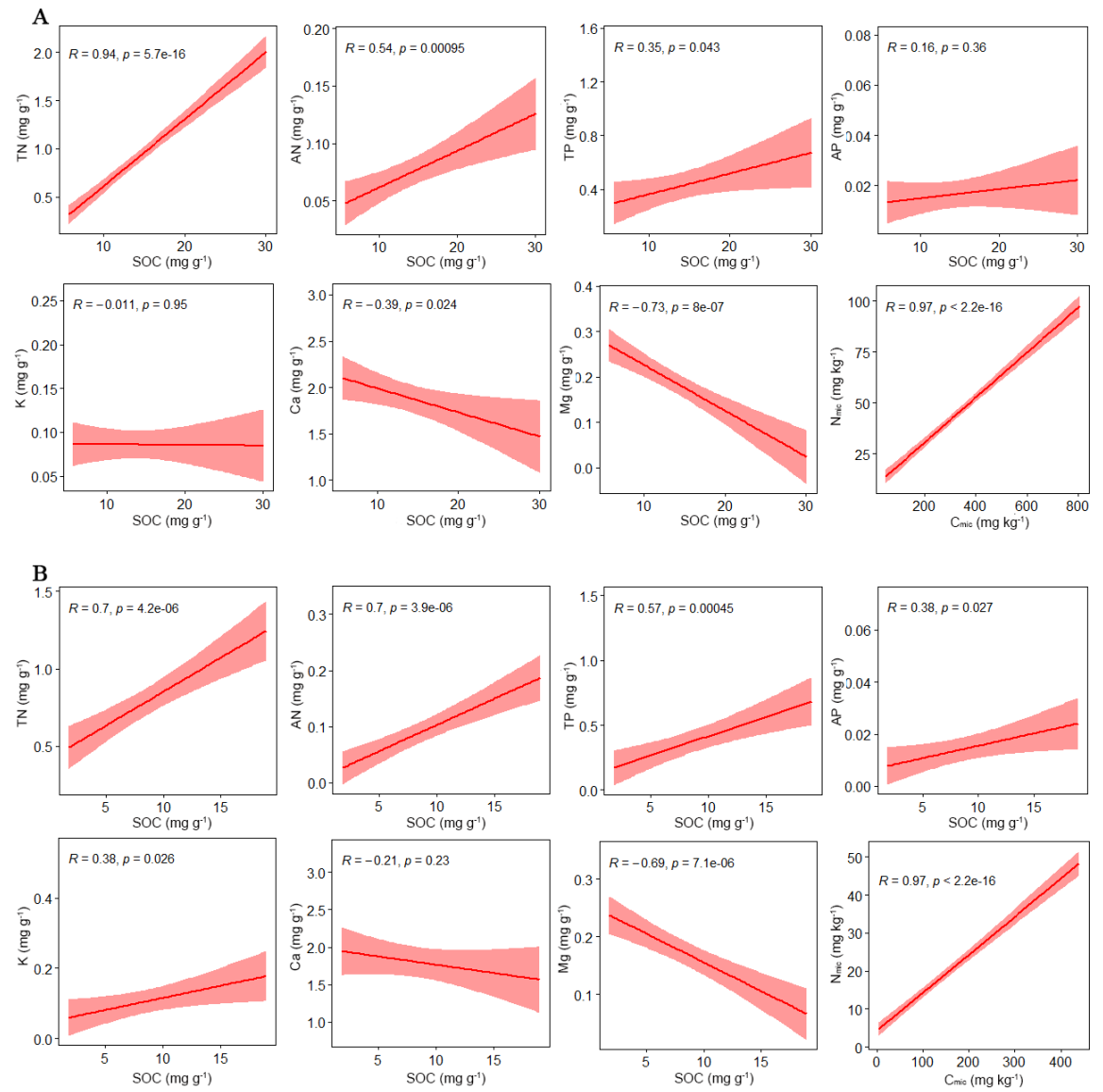